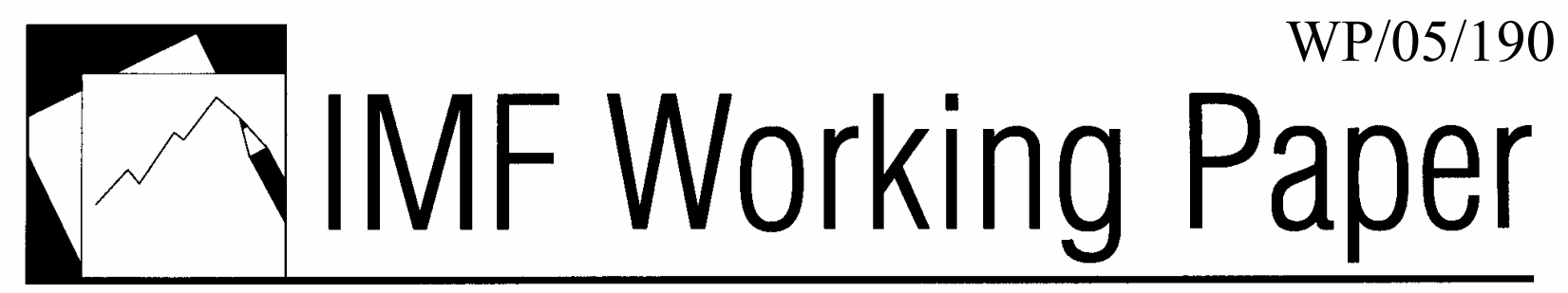

\title{
Investment Restrictions and Contagion in Emerging Markets
}

Anna Ilyina 


\title{
IMF Working Paper \\ International Capital Markets Department
}

\section{Investment Restrictions and Contagion in Emerging Markets}

\author{
Prepared by Anna Ilyina ${ }^{1}$ \\ Authorized for distribution by Ceyla Pazarbasioglu
}

September 2005

\begin{abstract}
This Working Paper should not be reported as representing the views of the IMF. The views expressed in this Working Paper are those of the author(s) and do not necessarily represent those of the IMF or IMF policy. Working Papers describe research in progress by the author(s) and are published to elicit comments and to further debate.

The objectives of this paper are: (1) to analyze an optimal portfolio rebalancing by a fund manager in response to a "volatility shock" in one of the asset markets, under sufficiently realistic assumptions about the fund manager's performance criteria and investment restrictions; and (2) to analyze the sensitivity of the equilibrium price of an asset to shocks originating in other fundamentally unrelated asset markets for a given mix of common investors. The analysis confirms that certain combinations of investment restrictions (notably short-sale constraints and benchmark-based performance criteria) can create additional transmission mechanisms for propagating shocks across fundamentally unrelated asset markets. The paper also discusses potential implications of recent and on-going changes in the investor base for emerging market securities for the asset price volatility.
\end{abstract}

JEL Classification Numbers: G11, G12

Keywords: Investment restrictions, Contagion, Emerging markets

Author(s) E-Mail Address: ailyina@imf.org

1 I am grateful to Jorge Roldos for useful comments and suggestions. 


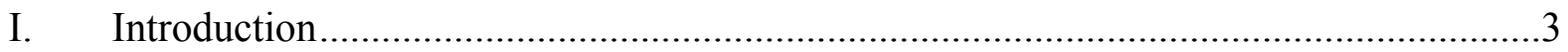

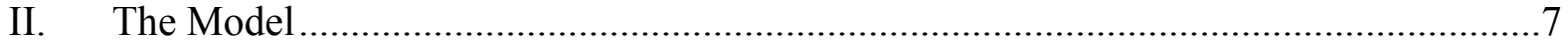

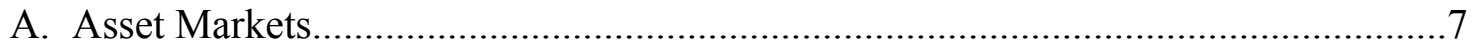

B. Types of Investors............................................................................................

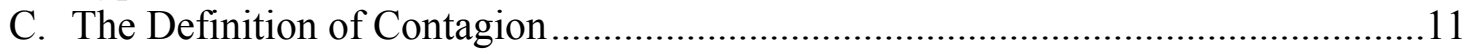

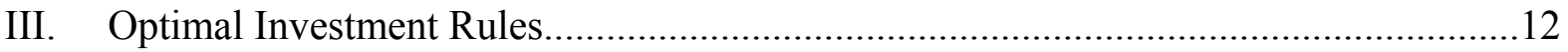

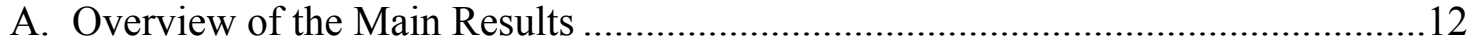

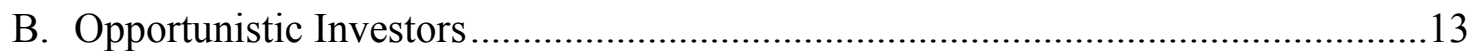

C. The Relative Return EM Investor with the "Risk-Return Trade-off" Rule............15

D. The Relative Return EM Investor with the TEV Minimization Rule......................18

E. The Absolute Return EM Investor .....................................................................20

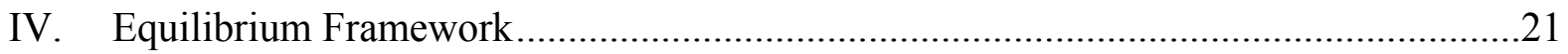

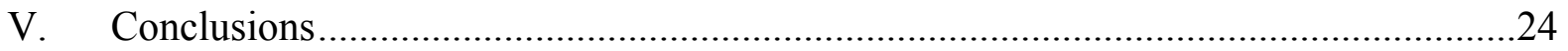

Tables

1. Asset Managers' Investment Mandates and Performance Criteria...............................10

2. The Sensitivity of Demand for Asset A to Higher (conditional) Variance of the

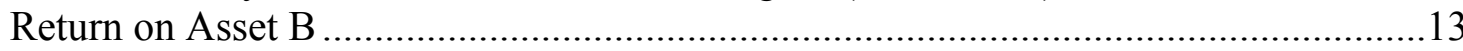

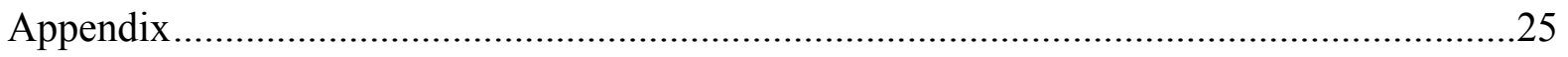

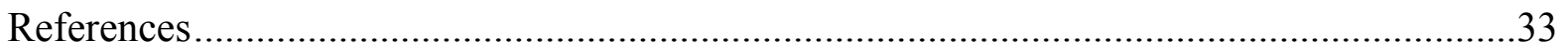




\section{INTRODUCTION}

A recurrent theme in the fast growing literature on financial contagion is contagion through portfolio re-allocations unrelated to "fundamental" factors, factors that determine the value that is, of an asset. In this literature, the behavior of investors who choose to adjust their exposure to a particular asset in response to new information unrelated to asset fundamentals may or may not be fully rational (the latter is often referred to as "herding" or "following the market"). ${ }^{2}$ For instance, a fund manager's decision to buy or sell an asset on news unrelated to the fundamental value of this asset may be rational in an environment where investors act strategically, taking into account the actions of other market participants; or in an environment where investors are price takers, but are subject to investment restrictions that create "artificial" links between their positions in the fundamentally unrelated markets. The latter will be the focus of this paper. ${ }^{3}$

The objectives of this paper are:

1. to analyze an optimal portfolio rebalancing by a fund manager in response to a "volatility shock" in one of the asset markets, under sufficiently realistic assumptions about the fund manager's performance criteria and investment restrictions; and,

2. to analyze the sensitivity of the equilibrium asset price to a shock originating in other asset markets, for a given mix of investors participating in several fundamentally unrelated markets.

Why are these issues important? First, when regulators design investment guidelines for various institutional investors, such as mutual funds, pension funds, and insurance companies, their first priority is investor protection, whereas the potential impact of the portfolio allocation decisions of institutional investors on asset price dynamics are rarely taken into account. Second, in less liquid markets (including most emerging markets) and, particularly, in those where foreign institutional investors account for a large share of asset holdings and turnover, portfolio rebalancing by large investors in response to local and external shocks may have significant implications for asset price movements. Thus, a better understanding of the role played by different types of institutional investors in propagating shocks across asset markets is critical to understanding the extent to which assets prices, particularly in emerging markets, are driven by factors unrelated to asset fundamentals.

Virtually all types of investors (local retail investors, foreign and domestic banks, mutual funds, and pension funds) are present in emerging markets (EMs). During the 1990s, the participation

2 See, for example, Bikhchandani and Sharma (2000) and Kaminsky and Reinhart (2000) for a review of different approaches toward modeling herding in financial markets.

${ }^{3}$ This paper is related to earlier joint work with Chakravorti and Lall (2003) in terms of the broad topic, but differs in terms of its focus and modeling framework. 
of foreign institutional investors in emerging debt and equity markets increased dramatically, driven by the capital account liberalization and improved credit fundamentals in many EMs, as well as by the relaxation of investment restrictions for institutional investors in mature markets. While it is difficult to come across a comprehensive data source on foreign holdings of EM securities, it is possible to gauge the proportions of the main types of foreign institutional investors in EMs by looking at the customer flows of the major market makers. For instance, based on JP Morgan's client data on foreign investor trading in emerging debt markets (EDM), ${ }^{4}$ the proportion of crossover investors (high-grade investors, in the chart below (Bayliss and Byun, 2005) in the EDM trading volume has been rising steadily since 1998, outpacing the share of dedicated EM mutual funds, while the share of hedge funds has picked up only during the past $2-3$ years. 5

\section{Share of JPM Trading Volume by Investor Type}

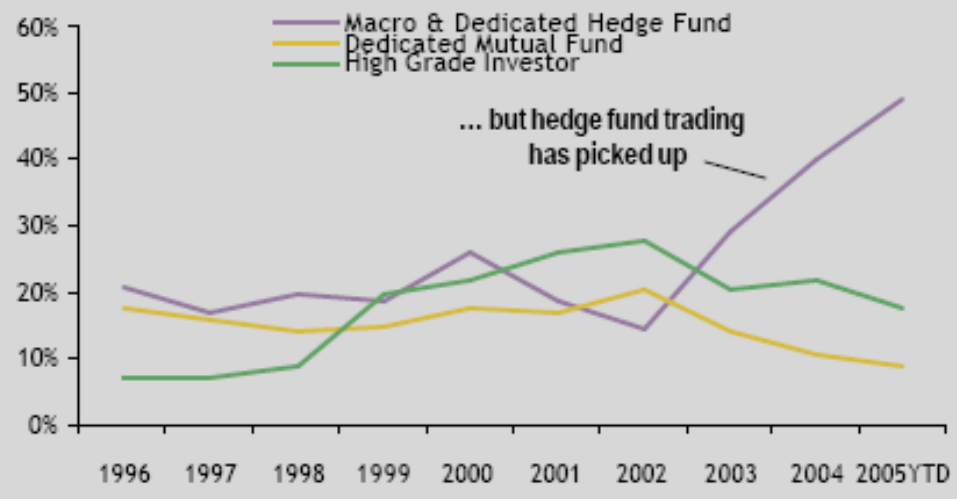

Source: Bayliss and Byun (2005).

${ }^{4}$ Emerging debt market (EDM) is the market for the dollar- or euro-denominated eurobonds issued by the emerging market sovereigns and corporates.

${ }^{5}$ The term "dedicated emerging market investor" typically refers to an asset manager that has a mandate to invest exclusively in emerging market securities. Such an investor is usually benchmarked against an emerging market index (i.e., his performance is measured relative to the performance of a particular benchmark portfolio). The term "crossover investor" typically refers to an asset manager who does not have an EM specific mandate, but can invest in the EM securities that are part of the asset class which is specified in his investment mandate (equity or fixed income). Such an investor may or may not be benchmarked against an index that includes EM assets (for instance, for the U.S. High-Grade or U.S. High-Yield bond fund manager, the EM dollar-denominated bond exposure represents an "out-of-index" bet; such investors would typically cross-over into EMs to pick up yield). 
However, the share of hedge funds and proprietory trading desks of investment banks (trading accounts, in the chart below ((Bayliss and Byun, 2005)) in total assets under management of EDM investors remains much smaller than the share of dedicated investors.

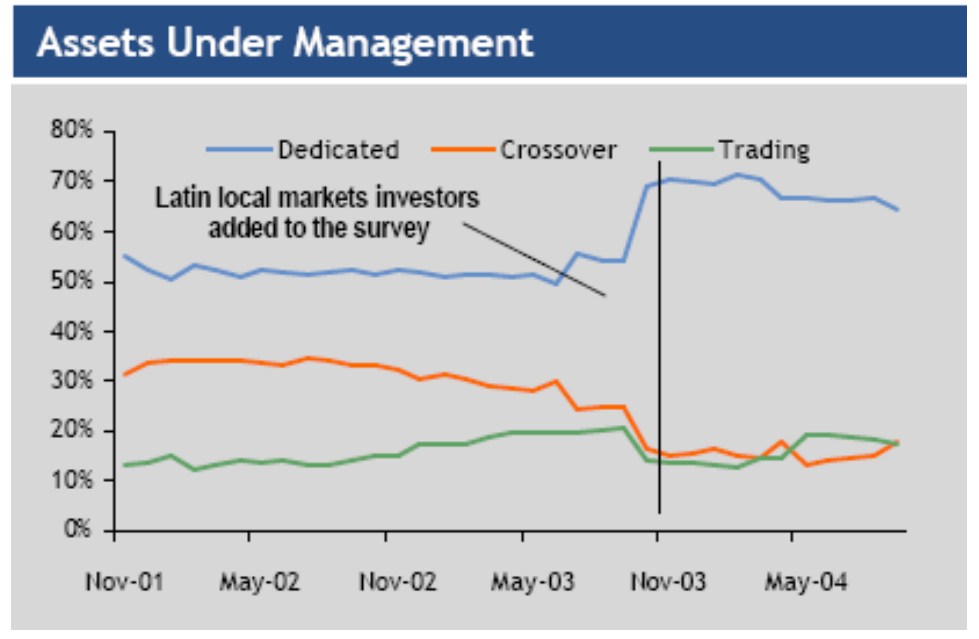

Source: Bayliss and Byun (2005).

Dedicated investors' allocations to the EM asset class are generally perceived to be more stable than those of opportunistic investors. Since opportunistic investors (crossover investors and hedge funds) are usually not measured against any EM benchmark, their investment decisions tend to be more sensitive to developments in competing asset classes. For example, the U.S. high-grade/high-yield funds may choose to adjust their EM allocations based on developments in the U.S. corporate bond market. As a result, crossover fund flows to emerging markets are perceived to be more volatile than those of dedicated EM mutual funds. Based on these observations, many analysts conclude that the inclusion of the EM assets in broader benchmark indices may reduce the overall volatility of portfolio flows to the individual emerging markets. This, however, may not necessarily be true, because the role of each type of fund manager in the transmission of volatility shocks across markets is also determined by his/her portfolio constraints. In particular, this paper shows that excessive price volatility in a particular asset market (which is unrelated to changes in the underlying asset fundamentals) can be generated by the portfolio reallocations of the fund managers that are subject to multiple investment restrictions.

Various strands of the contagion literature study the implications of institutional differences between investors for the "transmission" of shocks across asset markets. Papers by Schinasi and Smith (2000) and Calvo and Mendoza (2000) analyze contagion in the context of a singleinvestor decision problem. On the other hand, Kodres and Pritsker (2002), Kyle and Xiong (2001) and Danielsson, Shin and Zigrand (2004) study the impact of portfolio re-allocations by different types of investors on price dynamics in a general equilibrium framework. Instead of presenting a comprehensive overview of the literature on financial contagion, the rest of this section will focus on the discussion of the papers that are most closely related to the exercise presented here. 
Schinasi and Smith (2000) study the optimal portfolio rebalancing response to two types of shocks - an increase in volatility in one of the asset markets ("volatility event") and a capital loss ("capital event"). They consider different portfolio management rules within a partial equilibrium mean-variance framework, allowing portfolio managers to take both long and short positions (no short-sale constraints). They find that only in the case of a positive covariance between asset returns does a "volatility event" in one asset market lead to an adjustment of positions in other assets. ${ }^{6}$ Furthermore, a leveraged investor always reduces risky asset positions when the return on the leveraged portfolio falls below the cost of funding. In this paper, we consider a broader class of portfolio management rules, including rules in which the portfolio managers' compensation is explicitly linked to the performance of a benchmark index and where fund managers may be subject to short-sale constraints. In contrast with Schinasi and Smith (2000), asset values are assumed to be uncorrelated in this paper, so that any possible contagion effects could not be attributed to "fundamental" links between asset markets.

Calvo and Mendoza (2000) study the implications of institutional restrictions (in particular, the short-sale constraint) on investors' incentives to gather costly information and take positions based on their private information, as opposed to imitating arbitrary market portfolios. They find that, in the presence of short-sale constraints, the gains from acquiring information at a fixed cost may diminish as markets grow (i.e., as the number of assets increases). In this paper, the analysis is focused on what happens when the short-sale constraint is combined with other institutional restrictions, such as the benchmark-linked performance criterion, and whether this can create an additional transmission mechanism for contagion through portfolio rebalancing.

Danielsson, Shin and Zigrand (2004) investigate the implications of the wide-spread adoption of VaR (Value-at-Risk) risk management techniques on asset price dynamics in a general equilibrium framework. A comparison of the simulated dynamics of asset prices with the use of VaR techniques with the asset price dynamics without VaR reveals that: (1) prices are lower with VaR constraints; (2) troughs in the price paths with VaR constraints following a negative shock are deeper and longer; (3) the variance of returns is larger with VaR constraints than without them. ${ }^{7}$ These results raise more general concerns that the widespread use of certain types of investment constraints (including those that restrict the fund manager's portfolio choices in the interests of investor protection) may have a systematic negative impact on asset price dynamics.

\footnotetext{
${ }^{6}$ Schinasi and Smith (2000) argue that this is the most interesting and relevant case because asset returns are generally positively correlated across countries.

${ }^{7}$ It is not clear, however, whether VaR rules are "worse" than other types of constraints in terms of exacerbating asset price volatility. In the partial equilibrium framework, VaR rules do not seem to produce portfolio rebalancing dynamics that are very different from a variety of other portfolio management rules (see Schinasi and Smith 2000).
} 
The paper is organized as follows. Section II provides a stylized representation of the main types of institutional investors that are typically active in emerging markets. The optimal investment rules for different types of portfolio managers-given their performance criteria, investment mandate and specific investment restrictions-are derived in Section III, which also analyzes the optimal portfolio re-allocation decision in response to a particular type of shock. Finally, the equilibrium analysis presented in Section IV focuses on the question of how the composition of investor base for a particular asset determines the sensitivity of the equilibrium price to shocks originating in other asset markets.

\section{THe ModeL}

\section{A. Asset Markets}

Consider a simple discrete time environment with three risky assets (two emerging market assets $A$ and $B$ and a portfolio of mature market assets $Z)^{8}$ and one riskless asset - cash $(M)$, where emerging market assets $(A, B)$ are assumed to have higher return and higher volatility than the mature market portfolio $(Z)$. There are only two periods: the current period $(t=0)$ and the terminal period $(t=1)$. Investors make their portfolio decisions in period 0 , based on their expectations about asset values in the terminal period, and liquidate their positions/consume in period 1 . The gross return on asset $i$, for $i \in\{A, B, Z\}$, is

$$
R^{i} \equiv \frac{P_{1}^{i}}{P_{0}^{i}}
$$

where $P_{1}^{i}$ denotes the value of asset $i$ in the terminal period and $P_{0}^{i}$ denotes the equilibrium price determined by the supply and demand conditions in asset market $i$ in the current period.

The terminal values of all assets are normally distributed with means $\mu_{i}$ and variances $\sigma_{i}^{2}$, which are commonly known among investors. These probability distributions can be interpreted as representing uncertainty about the fundamental values of assets. In order to isolate the impact of portfolio allocation decisions by different types of investors on equilibrium prices in period 0 from any effect that may be due to fundamental links between asset markets, the terminal period values of assets traded in different markets are assumed to be uncorrelated, i.e., $\operatorname{Cov}\left(P_{1}^{i}, P_{1}^{k}\right)=0$, for any $i, k \in\{A, B, Z\}$.

${ }^{8}$ The emerging market assets A and B can also be viewed as portfolios of assets, for example, A could be a portfolio of the Latin American equities and B could be a portfolio of Asian equities. 
The equilibrium analysis presented in Section IV focuses on the derivation of the market clearing prices for emerging markets $A$ and $B$ for a given mix of investors participating in both mature and emerging markets. Assuming that both assets $A$ and $B$ are infinitely divisible and available to investors in fixed (inelastic) supply, let $S_{A}$ and $S_{B}$, denote the supplies of assets $A$ and $B$, respectively, and let $D_{J, A}$ and $D_{J, B}$ denote the aggregate demands by investor group $J$ for assets $A$ and $B$, respectively.

Then, the market clearing conditions are:

$$
\begin{aligned}
& \sum_{J} D_{J, A}=S_{A}, \\
& \sum_{J} D_{J, B}=S_{B} .
\end{aligned}
$$

Each investor group consists of a large number of investment funds, each with an initial capital of unity. Since each fund's capital is small relative to the supply of assets A and B, fund managers act as price takers in both markets.

\section{B. Types of Investors}

The fund manager's portfolio optimization problem is defined by his (1) investment mandate, (2) performance criterion and (3) portfolio management rule. A particular combination of (1)-(3) is usually chosen to align the incentives of fund manager with the risk-return preferences of end investors. Thus, the manager's compensation is typically linked to the performance of his/her investment portfolio, while investment restrictions are chosen so as to minimize "excessive" risk-taking by the portfolio manager. For instance, if the end investor is risk-averse and has a CARA type utility function, the investor would want to make sure that the fund manager's compensation is increasing in the expected portfolio return and decreasing in the variability of portfolio return (as in the "risk-return trade-off" rule, described below ). 9

\footnotetext{
${ }^{9}$ There is an extensive literature on delegated portfolio management that analyses the ways in which the incentives of fund managers can be aligned with the preferences of end investors under different assumptions about risk-aversion and information asymmetries. The detailed discussion of these issues is beyond the scope of this paper and in what follows, the analysis will focus on rules and restrictions that are standard in finance literature. Also, in what follows, no distinction will be made between "investors" and "fund managers."
} 


\section{(1) Investment Mandate}

The fund manager's investment mandate typically specifies the "asset class" that he/she can invest in (i.e., equity or fixed income instruments in a particular country or region) as well as restrictions on the use of leverage (short-sale constraints). For example, dedicated emerging market equity funds are only allowed to invest in the locally traded shares or ADRs/GDRs issued by the emerging market companies.

\section{(2) Performance Criteria}

The fund manager's performance criterion can be either absolute-measured as the return on capital under management, or relative-measured as the return on the fund's investment portfolio in excess of the benchmark portfolio return.

The majority of institutional investors, including pension funds, endowments and various collective investment schemes, are only allowed to use minimal leverage and only temporarily (either in the form of short-term bank credit or implicit in the derivatives positions) or no leverage at all. In contrast, hedge funds and the proprietary trading desks of investment banks may establish negative or positive exposures in any asset market. Investment funds that are not allowed to use leverage are often referred to as "real money" funds.

The institutional investors shown in the table below represent the main types of portfolio managers that currently operate in the international capital markets. Most "real money " funds also tend to be benchmarked against a particular index, while those fund managers that are allowed to use "unlimited" leverage (hedge funds, etc., where leverage is limited only by the internal risk management guidelines) tend to be absolute return driven. However, with the recent regulatory changes in the asset management industry, the boundaries between mutual funds and hedge funds are beginning to blur. ${ }^{10}$

${ }^{10}$ In the U.S. mutual fund industry, the decision by the U.S. Congress to repeal the short-sale restriction for mutual funds in 1997 and the Securities and Exchange Commision (SEC) decision to expand the allowable securities list for mutual funds led to the appearance of the first long-short mutual funds in 1998. Some of these "next generation" mutual funds are also reportedly using limited leverage and limited incentive fees, and are commonly referred to as "hedged mutual funds" (HMFs). According to industry experts, assets under the management of HMFs grew from $\$ 2.4$ billion in 1998 to about $\$ 6$ billion in 2002, which is still a very small fraction of the U.S. mutual fund industry assets (around $\$ 4$ trillion, as of end-2002). 
Table 1. Asset Managers’ Investment Mandates and Performance Criteria.

\begin{tabular}{|c|c|c|c|c|}
\hline \multicolumn{5}{|c|}{ Investment Mandate } \\
\hline Performance Criterion & Global/Real Money & EM/Real Money & Global/Leveraged & EM/Leveraged \\
\hline Relative Return & Pension Funds & EM Mutual Funds & $\ldots$ & $\ldots$ \\
\hline Absolute Return & $\ldots$ & $\ldots$ & $\begin{array}{c}\text { Global Hedge funds } \\
\text { Proprietary Trading Desks }\end{array}$ & EM Hedge Funds \\
\hline
\end{tabular}

Since the EM fund managers are often benchmarked against a particular emerging market index, ${ }^{11}$ let $R^{I}$ denote the gross return (per unit of capital) on the benchmark portfolio consisting of assets $A$ and $B$ :

$$
R^{I} \equiv \alpha R^{A}+(1-\alpha) R^{B}
$$

where $\alpha \in[0,1]$ is exogenously given, as the weights are typically determined by the proprietor of the index and are only modified periodically.

\section{(3) Portfolio Management Rules}

Portfolio management rules are designed to ensure that the incentives of portfolio managers' are aligned with the preferences of end-investors in terms of the risk-return properties of the investment portfolio. In what follows, we will consider two portfolio management rules that are commonly used in the fund management industry: the "risk-return trade-off" rule and the "tracking-error minimization" rule.

The "risk-return trade-off" rule gives a portfolio manager the flexibility to select both the return and the risk of his portfolio. For instance, in the case of an absolute return driven investor, it is an outcome of the following optimization problem:

$$
\text { Maximize } E\left(R^{P}\right)-\frac{1}{2} \operatorname{aVar}\left(R^{P}\right)
$$

\footnotetext{
${ }^{11}$ For dollar denominated emerging market sovereign bonds, the typical benchmark indices are JP Morgan's Emerging Market Bond Index Plus (EMBI+) and EMBI Global indices. For emerging market equities, the most commonly used benchmark index is Morgan Stanley Capital International (MSCI) Emerging Markets Free index.
} 
where $a$ denotes the coefficient of risk aversion.

For fund managers whose performance is measured relative to the EM benchmark portfolio, the "risk-return trade-off" rule would be an outcome of the following optimization problem:

$$
\text { Maximize } E\left(R^{P}-R^{I}\right)-\frac{1}{2} \operatorname{aVar}\left(R^{P}-R^{I}\right) \text {. }
$$

Another rule which is commonly used by relative-return funds is the "tracking-error variance minimization" (TEV) rule. This rule requires that fund managers achieve a certain target level of outperformance over the benchmark index, while minimizing the volatility of the "tracking error," i.e., the variability of the difference between the manager's portfolio return and the benchmark portfolio return. The manager solves:

$$
\begin{gathered}
\text { Minimize } \operatorname{Var}\left(R^{P}-R^{I}\right) \\
\text { Subject to: } E\left(R^{P}-R^{I}\right) \geq k
\end{gathered}
$$

where $k$ is the minimum ("target") level of relative outperformance. In the extreme case, the fund manager tries to "shadow" the benchmark index, which is often referred to as passive investing. 12

\section{The Definition of Contagion}

While there are many types of shocks that could affect asset fundamentals and be transmitted to other asset markets via portfolio rebalancing by common investors, this paper focuses on the demand/price response induced by one specific type of shock - a "volatility event." Following Schinasi and Smith (2000), we define "volatility event" at time $t$ as an increase in the (conditional) variance of an asset's return at time $t+1$.

Since the main concern is a potential sell-off in one of the emerging markets due to the actions of common investors in response to a shock originating in a fundamentally unrelated market, the following definition of contagion will be used throughout the paper. In the market equilibrium context, contagion is defined as a decline of the current period price of asset $i\left(P_{0}^{i}\right)$ in response to an increase in the (conditional) variance of the value of asset $j\left(P_{1}^{j}\right)$.

${ }^{12}$ According to the IOSCO report (2004), "passive management encompasses benchmark funds, which follow some indices with a very tight tracking error." 
Thus, in order to transmit volatility shock from market $j$ to market $i$, the investor's optimal demand function for asset $i$ has to have a non-zero sensitivity to an increase in the (conditional) variance of asset $j$. For example, in the case of a negative sensitivity, the investor would prefer to reduce his/her demand for asset $i$ when the (conditional) variance of return on asset $j$ goes up.

\section{OPTIMAL INVESTMENT RULES}

\section{A. Overview of the Main Results}

Before presenting the derivation of the optimal investment rules for different types of investors, the Table below gives an overview of the key results of the partial equilibrium analysis. More specifically, it shows three different types of the EM "real money" funds and the sensitivities of their optimal demand functions for asset A to a higher (conditional) return variance of asset B. For those investors whose performance is measured relative to the EM benchmark index, the term "overweight" ("O.W.") refers to the investment position in an asset which exceeds the benchmark portfolio weight of this asset and the term "underweight" ("U.W.") refers to the investment position in an asset which is below its benchmark portfolio weight. For certain configurations of parameter values, it is optimal for the EM fund manager to be fully invested in assets A and B, in which case the "no borrowing constraint" is binding and cash holdings are zero.

The main results are as follows:

- Relative return EM funds that follow the "risk-return trade-off" rule react to higher volatility in market $B$ by reducing their demand for asset A, only when they are fully invested in the EM assets and asset A is expected to outperform asset B (i.e., they have an overweight position in asset A).

- $\quad$ Relative return EM funds that follow the TEV minimization rule reduce their demand for asset $\mathrm{A}$ in response to higher volatility in market B only if their expected relative performance is at the "target" level and asset A is expected to underperform asset B (i.e., they have an underweight position in asset A).

- Absolute return EM funds that follow the "risk-return trade-off" rule never react to higher volatility in market B by reducing their demand for asset A. On the contrary, they prefer to increase their exposure to an asset if the variance of an alternative asset goes up (other things being equal), but do so only when they are fully invested in the EM assets.

The main conclusion is that the relative return EM funds that are subject to the short-sale constraints can potentially transmit (negative) volatility shocks across fundamentally unrelated markets, while absolute return driven funds do not transmit negative shocks. 
Table 2. The Sensitivity of Demand for Asset A to Higher (conditional) Variance of the Return on Asset B

Optimal Allocation Across EM Assets

\begin{tabular}{|c|c|c|c|c|}
\hline $\begin{array}{l}\text { Performance Criterion/ } \\
\text { Porfolio Management Rule }\end{array}$ & $\begin{array}{c}\text { Cash }=0 \\
\text { Asset } \mathrm{A}=\text { 'O.W.' }\end{array}$ & $\begin{array}{c}\text { Cash }=0 \\
\text { Asset A }=\text { 'U.W.' }\end{array}$ & $\begin{array}{c}\text { Cash }>0 \\
\text { Asset } \mathrm{A}=\text { 'O.W.' }\end{array}$ & $\begin{array}{c}\text { Cash }>0 \\
\text { Asset } \mathrm{A}=\text { 'U.W.' }\end{array}$ \\
\hline \multicolumn{5}{|l|}{ Relative Return } \\
\hline 'Risk-return trade-off' rule & Negative & Positive & 0 & 0 \\
\hline TEV rule & - & - & Positive & Negative \\
\hline \multicolumn{5}{|l|}{ Absolute Return } \\
\hline 'Risk-return trade-off' rule & Positive & Positive & 0 & 0 \\
\hline
\end{tabular}

How "special" are the circumstances under which the "no-borrowing" constraint is binding and the optimal cash holdings are equal to zero?

First, zero cash holdings are optimal for the configurations of parameter values, where the EM assets are expected to outperform the risk-free asset $\left(\frac{E\left(R^{A}\right)-R^{M}}{\operatorname{Var}\left(R^{A}\right)}+\frac{E\left(R^{B}\right)-R^{M}}{\operatorname{Var}\left(R^{B}\right)}>0\right)$, which does not seem implausible, since the risk premiums on EM assets are generally positive.

Second, the dedicated EM mutual funds tend to be "fully invested" most of the time and typically hold small positive amounts of cash (around 5 percent of total capital) for liquidity management purposes (to meet redemptions).

\section{B. Opportunistic Investors}

Consider the portfolio optimization problem of an opportunistic global fund manager, who invests in both mature and emerging market assets $(A, B$ and $Z$ ), whose performance is not measured relative to any benchmark index and who is not subject to the short-sale constraints.

Let $R^{O}$ denote the opportunistic fund manager's portfolio return, where $\phi$ is the proportion allocated to asset $A, \delta$ is the proportion allocated to asset $B$, and $\eta$ is the proportion allocated to asset $Z$ :

$$
R^{O}=\phi R^{A}+\delta R^{B}+\eta R^{Z}+(1-\phi-\delta-\eta) R^{M} .
$$


The portfolio optimization problem is

$$
\max _{\phi, \delta, \eta}\left\{\begin{array}{l}
\phi E\left(R^{A}\right)+\delta E\left(R^{B}\right)+\eta E\left(R^{Z}\right)+(1-\phi-\delta-\eta) R^{M} \\
-\frac{a}{2}\left(\phi^{2} \operatorname{Var}\left(R^{A}\right)+\delta^{2} \operatorname{Var}\left(R^{B}\right)+\eta^{2} \operatorname{Var}\left(R^{Z}\right)\right)
\end{array}\right\},
$$

which yields a standard solution, i.e.

$$
\begin{gathered}
\phi^{*}=\frac{E\left(R^{A}\right)-R^{M}}{\operatorname{aVar}\left(R^{A}\right)} \\
\delta^{*}=\frac{E\left(R^{B}\right)-R^{M}}{a \operatorname{Var}\left(R^{B}\right)} \\
\eta^{*}=\frac{E\left(R^{Z}\right)-R^{M}}{a \operatorname{Var}\left(R^{Z}\right)} .
\end{gathered}
$$

The properties of the opportunistic fund manager's optimal portfolio allocation are as follows:

a) The opportunistic fund manager has a long (short) position in an asset if it's expected risk-adjusted excess return is positive (negative).

b) Higher risk aversion induces the fund manager to scale back his risky asset positions.

c) Higher return variance of any risky asset causes the opportunistic manager to reduce his exposure to that asset, but does not affect other asset positions in his portfolio.

Thus, in this model, where fundamental values of assets are assumed to be uncorrelated, portfolio rebalancing by opportunistic investors does not transmit volatility across unrelated markets. ${ }^{13}$ In what follows, the behavior of opportunistic investors will be compared to the optimal behavior of other types of investors who face portfolio constraints.

${ }^{13}$ This may not be the case for all types of shocks. For instance, Schinasi and Smith (2000) analyze portfolio re-allocation decisions by leveraged risk-averse investors in response to "capital events" (capital loss), in which case they choose to scale back their risky asset exposures. 


\section{The Relative Return EM Investor with the "Risk-Return Trade-Off" Rule}

Let $R^{D}$ denote the gross return on the portfolio of an EM fund manager, where $\lambda$ is the proportion of capital invested in asset $A$ and $\tau$ is the proportion of capital invested in asset $B$, with $(1-\lambda-\tau)$ being the proportion held in cash:

$$
R^{D}=\lambda\left(R^{A}\right)+\tau\left(R^{B}\right)+(1-\lambda-\tau)\left(R^{M}\right) .
$$

Let $R^{D}-R^{I}$ denote the total excess return on the dedicated emerging market fund's portfolio over the benchmark portfolio return, i.e.,

$$
R^{D}-R^{I}=(\lambda-\alpha) R^{A}+(\tau-1+\alpha) R^{B}+(1-\lambda-\tau) R^{M} .
$$

The expected excess return and it's variance are

$$
\begin{gathered}
E\left(R^{D}-R^{I}\right)=(\lambda-\alpha) E\left(R^{A}\right)+(\tau-1+\alpha) E\left(R^{B}\right)+(1-\lambda-\tau) R^{M}, \\
\operatorname{Var}\left(R^{D}-R^{I}\right)=\left((\lambda-\alpha)^{2} \operatorname{Var}\left(R^{A}\right)+(\tau-1+\alpha)^{2} \operatorname{Var}\left(R^{B}\right)\right) .
\end{gathered}
$$

(Recall that the return on cash is a known constant $R^{M}$, and the covariance between the terminal period values of assets $A$ and $B$ is assumed to be equal to zero.)

Then, the fund manager maximizes the following objective function:

$$
E\left(R^{D}-R^{I}\right)-\frac{1}{2} \operatorname{aVar}\left(R^{D}-R^{I}\right)
$$

subject to the short-sale constraints (given the assumption that dedicated fund manager is not allowed to short risky assets or to borrow cash).

Thus, the optimization problem is as follows:

$$
\begin{gathered}
\max _{\lambda, \tau}\left\{\begin{array}{c}
(\lambda-\alpha)\left(E\left(R^{A}\right)\right)+(\tau-1+\alpha)\left(E\left(R^{B}\right)\right)+(1-\lambda-\tau) R^{M} \\
-\frac{a}{2}\left[(\lambda-\alpha)^{2} \operatorname{Var}\left(R^{A}\right)+(\tau-1+\alpha)^{2} \operatorname{Var}\left(R^{B}\right)\right]
\end{array}\right\} \\
\text { subject to: }\left\{\begin{array}{c}
\lambda \geq 0, \\
\tau \geq 0, \\
\lambda+\tau \leq 1 .
\end{array}\right.
\end{gathered}
$$


Proposition 1: Consider the solution of the EM fund manager's optimization problem (3.1), where the optimal holdings of both emerging market assets are positive.

(i) Zero cash holdings: For the region of parameter values where

$$
\frac{E\left(R^{A}\right)-R^{M}}{\operatorname{Var}\left(R^{A}\right)}+\frac{E\left(R^{B}\right)-R^{M}}{\operatorname{Var}\left(R^{B}\right)}>0 \text { and }-\alpha<\frac{E\left(R^{A}\right)-E\left(R^{B}\right)}{a\left(\operatorname{Var}\left(R^{A}\right)+\operatorname{Var}\left(R^{B}\right)\right)}<(1-\alpha),
$$

the "no-borrowing" constraint is binding and the optimal portfolio weights are:

$$
\begin{gathered}
\lambda^{*}=\frac{E\left(R^{A}\right)-E\left(R^{B}\right)}{a\left(\operatorname{Var}\left(R^{A}\right)+\operatorname{Var}\left(R^{B}\right)\right)}+\alpha \\
\tau^{*}=\frac{E\left(R^{B}\right)-E\left(R^{A}\right)}{a\left(\operatorname{Var}\left(R^{A}\right)+\operatorname{Var}\left(R^{B}\right)\right)}+(1-\alpha) .
\end{gathered}
$$

(ii) Positive cash holdings: For the region of parameter values where

$$
\frac{E\left(R^{A}\right)-R^{M}}{\operatorname{Var}\left(R^{A}\right)}+\frac{E\left(R^{B}\right)-R^{M}}{\operatorname{Var}\left(R^{B}\right)}<0 \text {, the optimal portfolio allocation is an interior }
$$

solution, where $0<\lambda^{* *}<1,0<\tau^{* *}<1$ and

$$
\begin{gathered}
\lambda^{* *}=\frac{E\left(R^{A}\right)-R^{M}}{\operatorname{aVar}\left(R^{A}\right)}+\alpha \\
\tau^{* *}=\frac{E\left(R^{B}\right)-R^{M}}{a \operatorname{Var}\left(R^{B}\right)}+(1-\alpha) .
\end{gathered}
$$

Interestingly, the optimal deviation from the benchmark portfolio allocation $\left(\frac{E\left(R^{A}\right)-E\left(R^{B}\right)}{a\left(\operatorname{Var}\left(R^{A}\right)+\operatorname{Var}\left(R^{B}\right)\right)}\right)$ does not depend on the value of $\alpha$. This implies that two fund managers who start out with portfolios in which the weights are determined by different benchmark indices (different $\alpha$ 's), would make the same trades, given that they have the same beliefs about asset fundamentals. ${ }^{14}$

14 This is similar to the result obtained by Roll (1992) in the TEV minimization framework. 
Corollaries 1.1 and 1.2 describe the sensitivities of the EM fund manager's optimal investment rule to changes in the level of risk aversion and conditional volatilities of the EM assets returns.

Corollary 1.1: Consider the solution of the EM fund manager's optimization problem, where optimal cash holdings are positive.

a) The fund manager has an overweight position in asset $A\left(\lambda^{* *}>\alpha\right)$ if $E\left(R^{A}\right)>R^{M}$ and he has an underweight position in asset $A\left(\lambda^{* *}<\alpha\right)$ if $E\left(R^{A}\right)<R^{M}$ (similarly, for asset $B)$. When both $E\left(R^{A}\right)<R^{M}$ and $E\left(R^{B}\right)<R^{M}$, the fund manager can have underweight positions in both asset, in which case he would hold a positive amount of cash;

b) Higher risk aversion reduces the demand for a risky asset, if the manager holds an overweight position, and increases the demand for a risky asset, if the manager holds an underweight position;

c) Higher variance of the return on a risky asset reduces demand for this asset if the manager has an overweight position and increases the demand for this asset if the fund manager has an underweight (but positive) exposure;

d) Higher variance of the return on a risky asset has no impact on the demand for an alternative risky asset, i.e. there are no volatility spillovers.

Thus, Corollary 1.1 implies that the relative return fund managers tend to move closer to the benchmark index, when either the return volatility and/or the risk aversion go up.

Corollary 1.2: Consider the solution of the EM fund manager's optimization problem, where optimal cash holdings are equal to zero.

a) The fund manager has an overweight position in asset $A$ (or equivalently, underweight position in asset $B)$ whenever $E\left(R^{A}\right)>E\left(R^{B}\right)$, and vice versa. If the expected returns on two risky assets are equal, the optimal portfolio weights are the same as the benchmark portfolio weights.

b) Same as (b) in Corollary 1.1;

c) Same as (c) in Corollary 1.1;

d) For overweight positions, the demand is decreasing in the variance of the return on the alternative risky asset, while for underweight positions, the demand for risky asset is increasing in the variance of the return on the alternative risky asset.

Corollary 1.2 implies that the tendency of the EM fund managers to move closer to the benchmark allocation in response to higher uncertainty about asset returns may cause volatility 
spillovers across unrelated markets (for some parameter values). Consider, for instance, the case when the fund manager's optimal exposures to both emerging markets is positive, with an overweight position in asset $A$ and an underweight position in asset $B$. Suppose there is a shock to market $B$ that causes an increase in $\operatorname{Var}\left(R^{B}\right)$. Then, in response to higher $\operatorname{Var}\left(R^{B}\right)$, the EM fund manager would prefer to reduce his exposure to asset $A$ and increase his exposure to asset $B$. Alternatively, suppose that there is a shock to market $A$, which causes an increase in $\operatorname{Var}\left(R^{A}\right)$, then the EM fund manager's optimal re-allocation would still involve reducing his exposure to asset $A$ and increasing his exposure to asset $B$, because that brings him closer to the benchmark portfolio allocation.

Thus, given an optimal portfolio allocation of the relative return fund manager following the "risk-return trade-off" rule, and given that the "no-borrowing" constraint is binding, the overweight positions exhibit negative sensitivity to "volatility events" in alternative asset markets, while underweight positions exhibit positive sensitivity to "volatility events" in alternative asset markets. Intuitively, this means that the fund manager would scale back his exposure to the outperforming asset and increase his exposure to underperforming asset in response "volatility event" in a fundamentally unrelated market.

\section{The Relative Return EM Investor with the TEV Minimization Rule}

Next, consider the portfolio optimization problem of an EM fund manager following the "tracking error variance" (TEV) minimization rule, i.e. he has to minimize the variance of tracking error conditional on a given level of expected outperformance relative to the EM benchmark index. The dedicated EM-TEV fund manager's optimization problem is as follows:

$$
\begin{gathered}
\max _{\lambda, \tau}\left\{-\left[(\lambda-\alpha)^{2} \operatorname{Var}\left(R^{A}\right)+(\tau-1+\alpha)^{2} \operatorname{Var}\left(R^{B}\right)\right]\right\} \\
\text { subject to: }\left\{\begin{array}{c}
\lambda \geq 0 \\
\tau \geq 0 \\
\lambda+\tau \leq 1 \\
(\lambda-\alpha) E R^{A}+(\tau-1+\alpha) E R^{B}+(1-\lambda-\tau) R^{M} \geq k
\end{array}\right.
\end{gathered}
$$

where parameter $k$ is the target level of outperformance, which is assumed to be positive and strictly greater than the return on cash.

Proposition 2: Consider the solution of the EM-TEV fund manager's optimization problem (3.2), where the optimal holdings of both emerging market assets are positive. The "noborrowing" constraint is not binding, cash holdings are positive and the optimal portfolio weights are 


$$
\begin{gathered}
\lambda^{* *}=\frac{(k)\left(E\left(R^{A}\right)-R^{M}\right) \operatorname{Var}\left(R^{B}\right)}{\left(E\left(R^{A}\right)-R^{M}\right)^{2} \operatorname{Var}\left(R^{B}\right)+\left(E\left(R^{B}\right)-R^{M}\right)^{2} \operatorname{Var}\left(R^{A}\right)}+\alpha \\
\tau^{* *}=\frac{(k)\left(E\left(R^{B}\right)-R^{M}\right) \operatorname{Var}\left(R^{A}\right)}{\left(E\left(R^{A}\right)-R^{M}\right)^{2} \operatorname{Var}\left(R^{B}\right)+\left(E\left(R^{B}\right)-R^{M}\right)^{2} \operatorname{Var}\left(R^{A}\right)}+(1-\alpha),
\end{gathered}
$$

where $0<\lambda^{* *}<1,0<\tau^{* *}<1$.

Corollary 2.1: Consider the solution of the EM-TEV fund manager's optimization problem described in Proposition 2.

a) The fund manager has an overweight position in asset $A$ whenever $E\left(R^{A}\right)>R^{M}$ (similarly, for asset B). ${ }^{15}$

b) The size of the optimal deviation from the benchmark portfolio (overweight/ underweight position) does not depend on the benchmark index weights, but does depend on the target level of outperformance vis-à-vis the benchmark portfolio (i.e., the parameter $k$ ).

c) For overweight positions, the demand for a risky asset is decreasing in the return variance of an alternative asset, while for underweight positions, the demand for a risky asset is increasing in the return variance of an alternative asset.

In contrast with the EM fund manager who follows the "risk-return trade-off" rule, the optimal allocation of an EM-TEV manager is such that his underweight asset positions exhibit negative sensitivity to "volatility events" in alternative asset markets, while his overweight positions exhibit positive sensitivity to "volatility events" in alternative asset markets. This is because volatility spillovers are generated when the constraint on the expected level of outperformance vis-à-vis the benchmark index (but not the "no-borrowing" constraint) is binding. Thus, a "volatility event" in one market may force the EM-TEV fund manager to scale back his exposure to a fundamentally unrelated asset, if the latter is underperforming. Such behavior would presumably exacerbate the selling pressure in an underperforming market, and magnify asset price volatility.

${ }^{15}$ Note that $k>R^{M}$, by assumption. 


\section{E. The Absolute Return EM Investor}

Consider the portfolio allocation of an absolute return EM fund manager, who can have long positions in both EM assets and cash, but cannot take short positions. This investor is not benchmarked against any index and follows the "risk-return trade-off" rule. The optimization problem is as follows:

$$
\begin{aligned}
& \max _{\lambda, \tau}\left\{\lambda E\left(R^{A}\right)+\tau E\left(R^{B}\right)+(1-\lambda-\tau) R^{M}-\right.\left.\frac{a}{2}\left[\lambda^{2} \operatorname{Var}\left(R^{A}\right)+\tau^{2} \operatorname{Var}\left(R^{B}\right)\right]\right\} \\
& \text { subject to: }\left\{\begin{array}{c}
\lambda \geq 0, \\
\tau \geq 0, \\
\lambda+\tau \leq 1 .
\end{array}\right.
\end{aligned}
$$

Proposition 3: Consider the solution of the EM fund manager's optimization problem (3.3), where his optimal holdings of all risky assets are positive.

(i) Zero cash holdings: For the region of parameter values where

$$
\frac{E\left(R^{A}\right)-R^{M}}{\operatorname{Var}\left(R^{A}\right)}+\frac{E\left(R^{B}\right)-R^{M}}{\operatorname{Var}\left(R^{B}\right)}>0 \text { and }-\alpha<\frac{E\left(R^{A}\right)-E\left(R^{B}\right)}{a\left(\operatorname{Var}\left(R^{A}\right)+\operatorname{Var}\left(R^{B}\right)\right)}<(1-\alpha),
$$

the "no-borrowing" constraint is binding and the optimal portfolio weights are:

$$
\begin{aligned}
\lambda^{*} & =\frac{E\left(R^{A}\right)-E\left(R^{B}\right)}{a\left(\operatorname{Var}\left(R^{A}\right)+\operatorname{Var}\left(R^{B}\right)\right)}+\frac{\operatorname{Var}\left(R^{B}\right)}{\operatorname{Var}\left(R^{A}\right)+\operatorname{Var}\left(R^{B}\right)} \\
\tau^{*} & =\frac{E\left(R^{B}\right)-E\left(R^{A}\right)}{a\left(\operatorname{Var}\left(R^{A}\right)+\operatorname{Var}\left(R^{B}\right)\right)}+\frac{\operatorname{Var}\left(R^{A}\right)}{\operatorname{Var}\left(R^{A}\right)+\operatorname{Var}\left(R^{B}\right)} .
\end{aligned}
$$

(ii) Positive cash holdings: For the region of parameter values where

$$
\frac{E\left(R^{A}\right)-R^{M}}{\operatorname{Var}\left(R^{A}\right)}+\frac{E\left(R^{B}\right)-R^{M}}{\operatorname{Var}\left(R^{B}\right)}<0 \text {, the optimal portfolio allocation is an interior }
$$

solution, where $0<\lambda^{* *}<1,0<\tau^{* *}<1$ and

$$
\lambda^{* *}=\frac{E\left(R^{A}\right)-R^{M}}{a \operatorname{Var}\left(R^{A}\right)}
$$




$$
\tau^{* *}=\frac{E\left(R^{B}\right)-R^{M}}{a \operatorname{Var}\left(R^{B}\right)} .
$$

It easy to verify that whenever $\lambda^{*}>0$, it is increasing in $\operatorname{Var}\left(R^{B}\right)$ and similarly, whenever $\tau^{*}>0$, it is increasing in $\operatorname{Var}\left(R^{A}\right)$. Thus, when the optimal portfolio allocation is such that the "no-borrowing" constraint is binding and the EM fund manager has positive exposures to both EM assets, he would prefer to increase his exposure to a risky asset in response to "volatility event" in an alternative asset market. Thus, dedicated EM fund managers who face the shortsale constraints, but are not benchmarked against any index, do not transmit negative volatility shocks across fundamentally unrelated markets.

\section{EQUILIBRIUM FRAMEWORK}

The derivation of the optimal investment rules for several types of portfolio managers, presented in the previous section, showed that certain investment restrictions (or combinations of portfolio constraints) could create a "link" between the fund manager's exposure to a risky asset and the expected performance of an alternative risky asset held in his portfolio. Even if asset markets are fundamentally uncorrelated, such "link" could serve as a mechanism for the transmission of negative "volatility shocks" across markets.

In what follows, this phenomenon will be investigated in the equilibrium context, where two types of fund managers operate in both emerging markets A and B: (1) the relative return EM funds with the "risk-return trade-off" rule (will be referred to as "dedicated emerging market funds") and (2) opportunistic investors. The market clearing prices of assets $A$ and $B$ will be derived, assuming that asset supplies in both markets are inelastic.

Suppose that $N$ dedicated emerging market funds and $M$ global opportunistic funds are present in both markets $A$ and $B$. For the sake of simplicity, in what follows, the net return on cash is assumed to be equal to zero. We also assume that dedicated emerging market funds start out with the benchmark portfolio allocation, and that their net demands for assets $A$ and $B$ are entirely driven by the need to rebalance their portfolios given the new information about asset values in period 1. We will focus on the case when the "no-borrowing" constraint is binding and the optimal cash holdings of dedicated investors are equal to zero

Market clearing conditions are as follows:

$$
S_{A}=N\left(\frac{\left(\mu_{A}\right)-\left(\mu_{B}\right)\left(P_{0}^{A} / P_{0}^{B}\right)}{a\left(\sigma_{A}^{2}+\sigma_{B}^{2}\left(P_{0}^{A} / P_{0}^{B}\right)^{2}\right)}\right)+M\left(\frac{\mu_{A}-P_{0}^{A}}{a \sigma_{A}^{2}}\right)
$$




$$
S_{B}=N\left(\frac{\left(\mu_{B}\right)-\left(\mu_{A}\right)\left(P_{0}^{B} / P_{0}^{A}\right)}{a\left(\sigma_{A}^{2}\left(P_{0}^{B} / P_{0}^{A}\right)^{2}+\sigma_{B}^{2}\right)}\right)+M\left(\frac{\mu_{B}-P_{0}^{B}}{a \sigma_{B}^{2}}\right),
$$

where $S_{A}, S_{B}$ are the quantities of assets $A$ and $B$, respectively, available to fund managers, and $P_{0}^{A}, P_{0}^{B}$ are the market clearing prices.

Let $x=P_{0}^{A} \quad y=P_{0}^{B} / P_{0}^{A}$, then (4.1) and (4.2) can be rewritten as follows:

$$
\begin{gathered}
S^{A}=N\left(\frac{\mu_{A}-\mu_{B}\left(\frac{1}{y}\right)}{a\left(\sigma_{A}^{2}+\sigma_{B}^{2}\left(\frac{1}{y}\right)^{2}\right)}\right)+M\left(\frac{\mu_{A}-x}{a \sigma_{A}^{2}}\right) \\
S^{B}=N\left(\frac{\mu_{B}-\mu_{A} y}{a\left(\sigma_{A}^{2} y^{2}+\sigma_{B}^{2}\right)}\right)+M\left(\frac{\mu_{B}-x y}{a \sigma_{B}^{2}}\right) .
\end{gathered}
$$

Solving the system of equations for $x$ and $y$, we obtain the following:

$$
\begin{gathered}
y=\frac{(M+N) \mu_{B}-a S_{B} \sigma_{B}^{2}}{(M+N) \mu_{A}-a S_{A} \sigma_{A}^{2}} \\
x=\frac{\left((M+N) \mu_{A}-a S_{A} \sigma_{A}^{2}\right)\left(A-(2 M+N) B+\left(M^{2}+M N\right) C\right)}{M\left(A-2(M+N) B+(M+N)^{2} C\right)},
\end{gathered}
$$

where

$$
\begin{gathered}
A=a^{2} \sigma_{A}^{2}\left(S_{B} \sigma_{B}^{2}\right)^{2}+a^{2} \sigma_{B}^{2}\left(S_{A} \sigma_{A}^{2}\right)^{2} \\
B=a S_{A} \mu_{A} \sigma_{A}^{2} \sigma_{B}^{2}+a S_{B} \mu_{B} \sigma_{A}^{2} \sigma_{B}^{2} \\
C=\sigma_{A}^{2}\left(\mu_{B}\right)^{2}+\sigma_{B}^{2}\left(\mu_{A}\right)^{2} .
\end{gathered}
$$


Proposition 5: Suppose that the number of opportunistic investors (M) is such that $M>\max \left\{\frac{a S_{A} \sigma_{A}^{2}}{\mu_{A}}, \frac{a S_{B} \sigma_{B}^{2}}{\mu_{B}}\right\}$, then the market clearing prices of assets $A$ and $B$ are well defined (positive).

Intuitively this means that, in order for both markets to clear, the number of opportunistic investors must be sufficiently large.

Proposition 6: In equilibrium, dedicated EM investors prefer to have an overweight position in asset $A$, when $\frac{S_{A} \sigma_{A}^{2}}{\mu_{A}}>\frac{S_{B} \sigma_{B}^{2}}{\mu_{B}}$, and an underweight position in asset $A$, when $\frac{S_{B} \sigma_{B}^{2}}{\mu_{B}}>\frac{S_{A} \sigma_{A}^{2}}{\mu_{A}}$. Note that the condition $\frac{S_{A} \sigma_{A}^{2}}{\mu_{A}}>\frac{S_{B} \sigma_{B}^{2}}{\mu_{B}}$, under which the EM investors would prefer to have an overweight in asset $A$, can be rewritten as follows:

$$
\left(\frac{\mu_{A}}{\mu_{B}}\right) /\left(\frac{\mu_{A}-\frac{a S_{A} \sigma_{A}^{2}}{(M+N)}}{\mu_{B}-\frac{a S_{B} \sigma_{B}^{2}}{(M+N)}}\right)>1 .
$$

The left hand side of (4.5) is the ratio of the return on asset $A$ to the return on asset $B$, evaluated at the market clearing prices. Thus, the EM dedicated investors prefer to have an overweight in asset $A$ when this ratio is greater than 1 .

Now, imagine that the only types of investors in emerging markets are opportunistic funds. Then, market clearing prices would be as follows:

$$
\begin{gathered}
\overline{\bar{P}}_{0}^{A}=\mu_{A}-\frac{a S_{A} \sigma_{A}^{2}}{M} \\
\overline{\bar{P}}_{0}^{B}=\mu_{B}-\frac{a S_{B} \sigma_{B}^{2}}{M},
\end{gathered}
$$

which are well defined (positive) whenever $M>\max \left\{\frac{a S_{A} \sigma_{A}^{2}}{\mu_{A}}, \frac{a S_{B} \sigma_{B}^{2}}{\mu_{A}}\right\}$. This also means that if opportunistic funds are the only investors in both markets, there are no volatility spillovers. 
Proposition 7: Suppose that $M>\max \left\{\frac{a S_{A} \sigma_{A}^{2}}{\mu_{A}}, \frac{a S_{B} \sigma_{B}^{2}}{\mu_{A}}\right\}$ and that $\frac{S_{A} \sigma_{A}^{2}}{\mu_{A}}>\frac{S_{B} \sigma_{B}^{2}}{\mu_{B}}$ (the dedicated EM investors would prefer to have an overweight position in asset $A$ ), then the market clearing price of asset $A$ is decreasing in $\sigma_{B}^{2}$.

The main implication of Proposition 7 is consistent with the results of the partial equilibrium analysis, i.e., whenever the EM fund managers' optimal portfolio allocation is such that they would like to have an overweight position in asset $\mathrm{A}$, the market clearing price of asset $A$ is a decreasing function of the (conditional) variance of the value of asset $B\left(\sigma_{B}^{2}\right)$. In other words, when dedicated EM investors have an overweight position in asset $\mathrm{A}$ and their no-borrowing constraint is binding, an increase in the uncertainty about the fundamental value of asset B forces them to scale back their exposure to asset A, putting downward pressure on the price of asset $\mathrm{A}$.

\section{Conclusions}

The results presented in this paper provide further support to the notion that the design of investment guidelines for institutional investors, which often has a narrow investor protection focus (the single fund manager's perspective), should also take into account the impact of portfolio rebalancing (induced by these rules) by a large number of fund managers on the asset price dynamics. A better understanding of these implications would involve a simulation of the dynamic interaction of different types of institutional investors facing portfolio constraints.

Some of the conclusions that emerge from the analysis presented in the paper are related to the roles of different types of institutional investors in emerging markets:

- $\quad$ The analysis confirms that opportunistic investors (such as hedge funds) can play a stabilizing role in asset markets when other market participants, which (collectively) have a significant market power, face tight investment restrictions. This, for instance, can be the case because opportunistic investors are able to take a contrarian position in the face of a sell-off induced by the actions of the tightly regulated "real money" funds reacting to a shock originating in a fundamentally unrelated market.

- $\quad$ The analysis presented in the paper also suggests that the inclusion of the EM securities in global equity or bond indices may not necessarily reduce the volatility of portfolio flows to emerging markets. While it is true that the inclusion of the EM securities in the global benchmark indices can broaden the investor base for these assets, it can also increase the volatility of flows due to "unnecessary" (unrelated to asset fundamentals) portfolio re-allocations. The latter may be due to the widespread use of short-sale constraints and benchmark-based performance criteria in the asset management industry. 


\section{Appendix}

\section{Proof of Proposition 1:}

The Lagrangian for the optimization problem (3.1) can be written as follows:

$$
\begin{gathered}
L=(\lambda-\alpha)\left(E\left(R^{A}\right)\right)+(\tau-1+\alpha)\left(E\left(R^{B}\right)\right)+(1-\lambda-\tau) R^{M} \\
-\frac{a}{2}\left[(\lambda-\alpha)^{2} \operatorname{Var}\left(R^{A}\right)+(\tau-1+\alpha)^{2} \operatorname{Var}\left(R^{B}\right)\right]+\varphi(1-\lambda-\tau)
\end{gathered}
$$

where $\varphi$ is the Lagrange multiplier associated with the "no-borrowing" constraint.

Assuming that $\lambda>0$ and differentiating $L$ with respect to $\lambda$ we get:

$$
\lambda=\frac{E R^{A}-R^{M}-\varphi}{\operatorname{aVar}\left(R^{A}\right)}+\alpha
$$

Assuming that $\tau>0$ and differentiating with respect to $\tau$ we get:

$$
\tau=\frac{E R^{B}-R^{M}-\varphi}{a \operatorname{Var}\left(R^{B}\right)}+(1-\alpha)
$$

The complementary slackness condition and the non-negativity constraint for the Lagrange multiplier associated with the "no borrowing" constraint are

$$
\varphi(1-\lambda-\tau)=0, \varphi \geq 0
$$

Thus, if the constraint does not bind, i.e. $\lambda+\tau<1$, then the multiplier must be $\varphi=0$ Alternatively, if the multiplier is positive $\varphi>0$, the constraint must be binding, i.e. $\lambda+\tau=1$

Suppose that $\varphi>0$ and the constraint is binding, i.e.

$$
\lambda+\tau=1
$$

Then, we can derive the optimal value of $\varphi$ from $(0.1)-(0.3)$

$$
\varphi=\frac{\left(E R^{A}-R^{M}\right) \operatorname{Var}\left(R^{B}\right)+\left(E R^{B}-R^{M}\right) \operatorname{Var}\left(R^{A}\right)}{\left(\operatorname{Var}\left(R^{A}\right)+\operatorname{Var}\left(R^{B}\right)\right)}
$$


which is positive whenever

$$
\frac{\left(E R^{A}-R^{M}\right)}{\operatorname{Var}\left(R^{A}\right)}+\frac{\left(E R^{B}-R^{M}\right)}{\operatorname{Var}\left(R^{B}\right)}>0
$$

Then, solving for the optimal portfolio weight $\lambda^{*}$, we have the following

$$
\lambda^{*}=\frac{E R^{A}-E R^{B}}{a\left(\operatorname{Var}\left(R^{A}\right)+\operatorname{Var}\left(R^{B}\right)\right)}+\alpha
$$

And solving for the optimal value of $\tau^{*}$, we get

$$
\tau^{*}=\frac{E R^{B}-E R^{A}}{a\left(\operatorname{Var}\left(R^{A}\right)+\operatorname{Var}\left(R^{B}\right)\right)}+(1-\alpha)
$$

Next, suppose that $\lambda+\tau<1$ and $\varphi=0$

$\lambda+\tau<1$ is then equivalent to $\frac{\left(E R^{A}-R^{M}\right)}{\operatorname{Var}\left(R^{A}\right)}+\frac{\left(E R^{B}-R^{M}\right)}{\operatorname{Var}\left(R^{B}\right)}<0$, which can hold only if the expected return on at least one of the emerging market assets is lower than the return on cash.

On the other hand, $\lambda>0$ and $\tau>0$ imply that

$$
\frac{E R^{A}-R^{M}}{\operatorname{Var}\left(R^{A}\right)}+\alpha>0 \text { and } \frac{E R^{B}-R^{M}}{\operatorname{Var}\left(R^{B}\right)}+(1-\alpha)>0
$$

Thus, when $\frac{E R^{A}-R^{M}}{\operatorname{Var}\left(R^{A}\right)}+\frac{E R^{B}-R^{M}}{\operatorname{Var}\left(R^{B}\right)}<0, \frac{E R^{A}-R^{M}}{\operatorname{Var}\left(R^{A}\right)}+\alpha>0$ and $\frac{E R^{B}-R^{M}}{\operatorname{Var}\left(R^{B}\right)}+(1-\alpha)>0$,

the optimal demand functions are

$$
\lambda^{* *}=\frac{E R^{A}-R^{M}}{\operatorname{Var}\left(R^{A}\right)}+\alpha \text { and } \tau^{* *}=\frac{E R^{B}-R^{M}}{\operatorname{Var}\left(R^{B}\right)}+(1-\alpha)
$$


Finally, it is not difficult to verify that the value of the objective function $V\left(\lambda^{* *}, \tau^{* *}\right)$ is indeed greater than $V(0,0)$ when $\frac{E R^{A}-R^{M}}{\operatorname{Var}\left(R^{A}\right)}+\alpha>0$ and $\frac{E R^{B}-R^{M}}{\operatorname{Var}\left(R^{B}\right)}+(1-\alpha)>0$.

\section{Proof of Corollary 1.1:}

c) This is because by moving closer to the benchmark portfolio allocation, the fund manager can reduce the variance of his expected compensation. For instance, suppose that the fund manager has a positive/underweight exposure to asset $A$, i.e. $E\left(R^{A}\right)-R^{M}<0$ and $\frac{E\left(R^{A}\right)-R^{M}}{\operatorname{aVar}\left(R^{A}\right)}+\alpha>0$, then higher $\operatorname{Var}\left(R^{A}\right)$ would induce her to increase exposure to this asset.

d) This is because a reduction (increase) of the dedicated investor's position in one asset market is associated with the increase (decrease) of cash holdings, but not the holdings of other risky asset.

\section{Proof of Corollary 1.2:}

d) It is straightforward to verify that $\frac{\partial \alpha^{*}}{\partial \operatorname{Var}\left(R^{B}\right)}>0$, whenever $E\left(R^{A}\right)-E\left(R^{B}\right)<0$, and $\frac{\partial \alpha^{*}}{\partial \operatorname{Var}\left(R^{B}\right)}<0$, whenever $E\left(R^{A}\right)-E\left(R^{B}\right)>0$.

\section{Proof of Proposition 2:}

The Lagrangian for the optimization problem (3.2) can be written as follows:

$$
\begin{aligned}
& L=\gamma\left((\lambda-\alpha) E R^{A}+(\tau-1+\alpha) E R^{B}+(1-\lambda-\tau) R^{M}-k\right) \\
& -\left((\lambda-\alpha)^{2} \operatorname{Var}\left(R^{A}\right)+(\tau-1+\alpha)^{2} \operatorname{Var}\left(R^{B}\right)\right)+\varphi(1-\lambda-\tau)
\end{aligned}
$$

where $\gamma$ is the Lagrange multiplier associated with the constraint

$$
(\lambda-\alpha) E R^{A}+(\tau-1+\alpha) E R^{B}+(1-\lambda-\tau) R^{M} \geq k
$$

and $\varphi$ is the Lagrange multiplier associated with the constraint

$$
\lambda+\tau \leq 1
$$


Assuming that $\lambda>0$ and differentiating $L$ with respect to $\lambda$, we have

$$
\lambda=\frac{\gamma\left(E R^{A}-R^{M}\right)-\varphi}{2 \operatorname{Var}\left(R^{A}\right)}+\alpha
$$

Assuming that $\tau>0$ and differentiating with respect to $\tau$, we have

$$
\tau=\frac{\gamma\left(E R^{B}-R^{M}\right)-\varphi}{2 \operatorname{Var}\left(R^{B}\right)}+(1-\alpha)
$$

The complementary slackness conditions and corresponding non-negativity constraints are as follows:

$$
\begin{gathered}
\varphi(1-\lambda-\tau)=0, \varphi \geq 0 \\
\gamma\left((\lambda-\alpha) E R^{A}+(\tau-1+\alpha) E R^{B}+(1-\lambda-\tau) R^{M}-k\right)=0, \gamma \geq 0
\end{gathered}
$$

Suppose that $\gamma>0$ and $\varphi=0$, then we can derive the optimal values of $\lambda, \tau$ and $\gamma$ from $(0.4),(0.5)$ and $(0.7)$

$$
\begin{gathered}
\gamma=\frac{2 k \operatorname{Var}\left(R^{A}\right) \operatorname{Var}\left(R^{B}\right)}{\left(E R^{A}-R^{M}\right)^{2} \operatorname{Var}\left(R^{B}\right)+\left(E R^{B}-R^{M}\right)^{2} \operatorname{Var}\left(R^{A}\right)} \\
\lambda^{* *}=\frac{(k)\left(E R^{A}-R^{M}\right) \operatorname{Var}\left(R^{B}\right)}{\left(E R^{A}-R^{M}\right)^{2} \operatorname{Var}\left(R^{B}\right)+\left(E R^{B}-R^{M}\right)^{2} \operatorname{Var}\left(R^{A}\right)}+\alpha \\
\tau^{* *}=\frac{(k)\left(E R^{B}-R^{M}\right) \operatorname{Var}\left(R^{A}\right)}{\left(E R^{A}-R^{M}\right)^{2} \operatorname{Var}\left(R^{B}\right)+\left(E R^{B}-R^{M}\right)^{2} \operatorname{Var}\left(R^{A}\right)}+(1-\alpha)
\end{gathered}
$$

Note that since we have assumed that $\varphi=0$, it must be the case that $\lambda+\tau<1$, i.e. 


$$
\frac{(k)\left(E R^{A}-R^{M}\right) \operatorname{Var}\left(R^{B}\right)+(k)\left(E R^{B}-R^{M}\right) \operatorname{Var}\left(R^{A}\right)}{\left(E R^{A}-R^{M}\right)^{2} \operatorname{Var}\left(R^{B}\right)+\left(E R^{B}-R^{M}\right)^{2} \operatorname{Var}\left(R^{A}\right)}<0
$$

since the denominator is always positive, it must be the case that

$$
\frac{E R^{A}-R^{M}}{\operatorname{Var}\left(R^{A}\right)}+\frac{E R^{A}-R^{M}}{\operatorname{Var}\left(R^{B}\right)}<0
$$

i.e., the sum of risk-adjusted excess returns must be negative.

Suppose that $\varphi>0$ and $\gamma=0$, then

$$
\begin{gathered}
\lambda=\frac{-\varphi}{2 \operatorname{Var}\left(R^{A}\right)}+\alpha \\
\tau=\frac{-\varphi}{2 \operatorname{Var}\left(R^{B}\right)}+(1-\alpha)
\end{gathered}
$$

and investor must be fully invested in assets $\mathrm{A}$ and $\mathrm{B}$ and hold no cash, i.e. $1-\lambda-\tau=0$ is equivalent to $\varphi\left(-\operatorname{Var}\left(R^{A}\right)-\operatorname{Var}\left(R^{B}\right)\right)=0$, which holds only if $\varphi=0$, which contradicts our assumption that $\varphi>0$.

Suppose that none of the constraints are binding, i.e. $\varphi=0$ and $\gamma=0$, then

$$
\begin{gathered}
\lambda=\alpha \\
\tau=(1-\alpha)
\end{gathered}
$$

but then it must be the case the cash non-negativity constraint is binding, which contradicts our assumption. 


\section{Proof of Corollary 2.1:}

$\frac{d \lambda^{* *}}{d \operatorname{Var}\left(R^{B}\right)}>0 \Leftrightarrow\left(k-R^{M}\right)\left(E R^{A}-R^{M}\right)\left(E R^{B}-R^{M}\right)^{2} \operatorname{Var}\left(R^{A}\right)>0 \Leftrightarrow E R^{A}>R^{M}$

\section{Proof of Proposition 5:}

The market clearing prices can be rewritten as follows:

$$
\begin{aligned}
& \bar{P}_{0}^{A}=\frac{\left((M+N) \mu_{A}-a S_{A} \sigma_{A}^{2}\right) F}{M \cdot G} \\
& \bar{P}_{0}^{B}=\frac{\left((M+N) \mu_{B}-a S_{B} \sigma_{B}^{2}\right) F}{M \cdot G}
\end{aligned}
$$

where $\mathrm{F}$ and $\mathrm{G}$ are as follows:

$$
\begin{gathered}
F=\sigma_{B}^{2}\left(M \mu_{A}-a S_{A} \sigma_{A}^{2}\right)\left((M+N) \mu_{A}-a S_{A} \sigma_{A}^{2}\right)+\sigma_{A}^{2}\left(M \mu_{B}-a S_{B} \sigma_{B}^{2}\right)\left((M+N) \mu_{B}-a S_{B} \sigma_{B}^{2}\right) \\
G=\sigma_{B}^{2}\left(M \mu_{A}-a S_{A} \sigma_{A}^{2}\right)^{2}+\sigma_{A}^{2}\left(M \mu_{B}-a S_{B} \sigma_{B}^{2}\right)^{2}
\end{gathered}
$$

Since $G$ is always positive, the sign of $P_{0}^{A}$ (or $P_{0}^{B}$ ) depends on the sign of the numerator. It is straightforward to verify that the market clearing prices are positive whenever:

(i) for any $N$ and $\frac{S_{A} \sigma_{A}^{2}}{\mu_{A}}>\frac{S_{B} \sigma_{B}^{2}}{\mu_{B}}, M$ is such that $M>\max \left\{\frac{a S_{A} \sigma_{A}^{2}}{\mu_{A}}\right\}$

(ii) for any $N$ and $\frac{S_{B} \sigma_{B}^{2}}{\mu_{B}}>\frac{S_{A} \sigma_{A}^{2}}{\mu_{A}}, M$ is such that $M>\max \left\{\frac{a S_{B} \sigma_{B}^{2}}{\mu_{B}}\right\}$

Note that when $M>\max \left\{\frac{a S_{A} \sigma_{A}^{2}}{\mu_{A}}, \frac{a S_{B} \sigma_{B}^{2}}{\mu_{A}}\right\}, F$ is positive for any parameter values $a, \mu_{A}, \mu_{A}, \sigma_{A}^{2}, \sigma_{B}^{2}, S_{A}, S_{B}$ 


\section{Proof of Proposition 6:}

The dedicated investor's demand for asset $A$ evaluated at the market clearing prices is as follows:

$$
\frac{\mu_{A}\left((M+N) \mu_{B}-a S_{B} \sigma_{B}^{2}\right)^{2}-\mu_{B}\left((M+N) \mu_{A}-a S_{A} \sigma_{A}^{2}\right)\left((M+N) \mu_{B}-a S_{B} \sigma_{B}^{2}\right)}{a\left(\sigma_{A}^{2}\left((M+N) \mu_{B}-a S_{B} \sigma_{B}^{2}\right)^{2}+\sigma_{B}^{2}\left((M+N) \mu_{A}-a S_{A} \sigma_{A}^{2}\right)^{2}\right)}
$$

assuming that the market clearing prices are well defined (which implies that $\left.\left((M+N) \mu_{B}-a S_{B} \sigma_{B}^{2}\right)>0\right)$, the expression (0.8) is positive whenever $\frac{S_{A} \sigma_{A}^{2}}{\mu_{A}}>\frac{S_{B} \sigma_{B}^{2}}{\mu_{B}}$.

The dedicated investor's demand for asset $B$ evaluated at the market clearing prices is as follows:

$$
\frac{\left(\mu_{B}\left((M+N) \mu_{A}-a S_{A} \sigma_{A}^{2}\right)-\mu_{A}\left((M+N) \mu_{B}-a S_{B} \sigma_{B}^{2}\right)\right)\left((M+N) \mu_{A}-a S_{A} \sigma_{A}^{2}\right)}{a\left(\sigma_{A}^{2}\left((M+N) \mu_{B}-a S_{B} \sigma_{B}^{2}\right)^{2}+\sigma_{B}^{2}\left((M+N) \mu_{A}-a S_{A} \sigma_{A}^{2}\right)^{2}\right)}
$$

assuming that the market clearing prices are well defined (which implies that $\left.\left((M+N) \mu_{A}-a S_{A} \sigma_{A}^{2}\right)>0\right)$, the expression (0.9) is positive whenever $\frac{S_{A} \sigma_{A}^{2}}{\mu_{A}}<\frac{S_{B} \sigma_{B}^{2}}{\mu_{B}}$.

\section{Proof of Proposition 7:}

Differentiating $\bar{P}_{0}^{A}$ with respect to $\sigma_{B}^{2}$ and simplifying, we obtain the following expression

$$
\frac{\partial \bar{P}_{0}^{A}}{\partial \sigma_{B}^{2}}=\frac{\left((M+N) \mu_{A}-a S_{A} \sigma_{A}^{2}\right)}{M}\left(\frac{N \cdot Q}{G^{2}}\right)
$$

where

$$
\begin{aligned}
Q= & \sigma_{B}^{2}\left((M+N) \mu_{A}-a S_{A} \sigma_{A}^{2}\right)\left(\left(\frac{a S_{B} \sigma_{B}^{2}}{\mu_{B}}\right)^{2} \mu_{A}-(M+N) a S_{A} \sigma_{A}^{2}\right) \\
& +\sigma_{A}^{2}\left((M+N) \mu_{B}-a S_{B} \sigma_{B}^{2}\right)\left(\left(\frac{a S_{B} \sigma_{B}^{2}}{\mu_{B}}\right)^{2} \mu_{B}-(M+N) a S_{B} \sigma_{B}^{2}\right)
\end{aligned}
$$


The sign of $\frac{\partial \bar{P}_{0}^{A}}{\partial \sigma_{B}^{2}}$ depends on the sign of $Q$. Suppose that $M>\max \left\{\frac{a S_{A} \sigma_{A}^{2}}{\mu_{A}}, \frac{a S_{B} \sigma_{B}^{2}}{\mu_{A}}\right\}$, then it must be the case that $\left((M+N) \mu_{A}-a S_{A} \sigma_{A}^{2}\right)>0,\left((M+N) \mu_{B}-a S_{B} \sigma_{B}^{2}\right)>0$ and $\left(\left(\frac{a S_{B} \sigma_{B}^{2}}{\mu_{B}}\right)^{2} \mu_{B}-(M+N) a S_{B} \sigma_{B}^{2}\right)<0$.

Then, $Q$ is negative whenever $\left(\frac{a S_{B} \sigma_{B}^{2}}{\mu_{B}(M+N)}\right)^{2}<\frac{a S_{A} \sigma_{A}^{2}}{\mu_{A}(M+N)}$ and positive whenever $\left(\frac{a S_{B} \sigma_{B}^{2}}{\mu_{B}(M+N)}\right)^{2}>\frac{a S_{A} \sigma_{A}^{2}}{\mu_{A}(M+N)}$.

Note that $\frac{a S_{B} \sigma_{B}^{2}}{\mu_{B} M}<1$ and $\frac{a S_{A} \sigma_{A}^{2}}{\mu_{A} M}<1$ (by assumption).

Then, $\frac{a S_{B} \sigma_{B}^{2}}{\mu_{B}(M+N)}<1$ and $\frac{a S_{A} \sigma_{A}^{2}}{\mu_{A}(M+N)}<1$ must be true as well.

Finally, since $\frac{S_{A} \sigma_{A}^{2}}{\mu_{A}}>\frac{S_{B} \sigma_{B}^{2}}{\mu_{B}}$ (by assumption), then $\left(\frac{a S_{B} \sigma_{B}^{2}}{\mu_{B}(M+N)}\right)^{2}<\frac{a S_{A} \sigma_{A}^{2}}{\mu_{A}(M+N)}$ for any $a, \mu_{A}, \mu_{A}, \sigma_{A}^{2}, \sigma_{B}^{2}, S_{A}, S_{B}$ and $\frac{\partial \bar{P}_{0}^{A}}{\partial \sigma_{B}^{2}}<0$. 


\section{References}

Bayliss, Jonathan and Jennie Byun, 2005, "Emerging Markets as an Asset Class,” JPMorgan Emerging Markets Research, April.

Bikhchandani, Sushil, and Sunil Sharma, 2000, "Herd Behavior in Financial Markets-A Review," IMF Working Paper No. 00/48 (Washington: International Monetary Fund).

Calvo, Guillermo A., and Enrique G. Mendoza, 2000, "Rational Contagion and the Globalization of Securities Markets," Journal of International Economics, Vol. 51, pp. 79-113.

Chakravorti, Sujit, Anna Ilyina, and Subir Lall, 2003, "Managerial Incentives and Financial Contagion," Working Paper (Chicago: Federal Reserve Bank of Chicago), November.

Danielsson, Jon, Hyun Song Shin, and Jean-Pierre Zigrand, 2004, ’The Impact of Risk Regulation on Price Dynamics" Journal of Banking and Finance, Vol. 28, pp. 1069-87.

International Organization of Securities Commission, 2004, "Index Funds and the Use of Indices by the Asset Management Industry," November.

Kaminsky, G.L., and Carmen M. Reinhart, 2000, ”On Crises, Contagion, and Confusion," Journal of International Economics, Vol. 51, pp. 145-68.

Kodres, Laura E., and Matthew Pritsker, 2002, "A Rational Expectations Model of Financial Contagion," Journal of Finance, Vol. 62, pp. 769-99.

Kyle, Albert S., and Wei Xiong, 2001, "Contagion as a Wealth Effect," Journal of Finance Vol. 56, pp. 1401-40.

Roll, Richard, 1992, "A Mean-Variance Analysis of Tracking Error," The Journal of Portfolio Management, Vol. 18 Summer, pp. 13-22.

Schinasi, Garry J., and R. Todd Smith, 2000, "Portfolio Diversification, Leverage, and Financial Contagion," IMF Staff Papers, Vol. 47, No. 2, pp. 15. 